إدراك الخطر الصحي وعلاقته بالثعور بالمسؤولية لاى الطلاب الوافدين بجامعة إفريقيا العالمية في ظل جائحة كورونا

Health Risk Perception and its Relationship to Sense of Responsibility among International Students at International University of Africa during the COVID-19 Pandemic
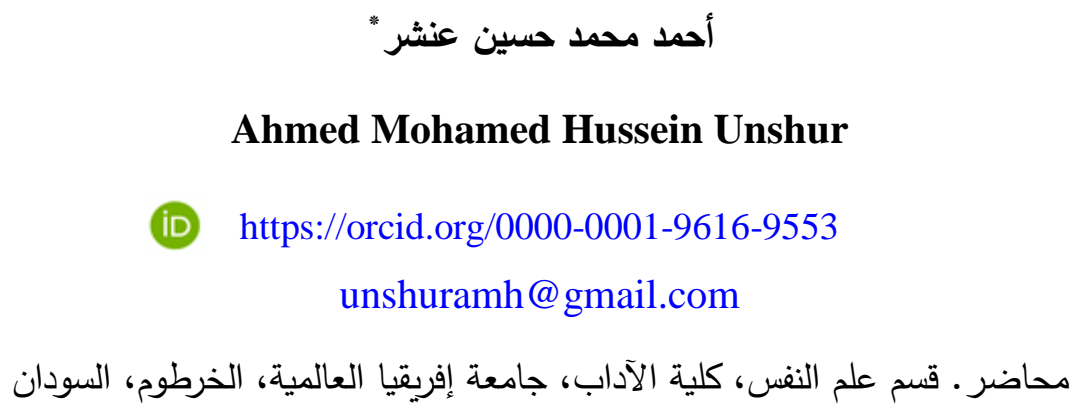

Lecturer. Department of Psychology, International University of Africa, Khartoum, Sudan

نصرالدين أحمد إدريس الدومه

Nasreldein Ahmed Idriss Aldouma

(iD https://orcid.org/0000-0001-9318-7035

wddnimr@yahoo.com

أستاذ مشارك. قسم علم النفس، كلية الآداب، جامعة إفريقيا العالمية، الخرطوم، السودان

Associate Professor. Department of Psychology, International University of Africa, Khartoum, Sudan 
هدفت الدراسة الحالية إلى الكثف عن العلاقة بين إدراك الخطر الصحي والثعور بالمسؤولية لاى الطلاب الوافدين بجامعة إفريقيا العالمية في ظل جائحة كورونا (COVID-19)، وتحديد مستوى إدراك الخطر الصحي والفروق تبعاً لمتغيرات النوع، العمر، التخصص الدراسي، والقارة. اتبعت الدراسة الدنهج الوصفي الارتباطي. تكونت عينة الدراسة من (n=149) طالبا وطالبة تم اختيارهم بالطريقة القصدية. تم استخدام مقياسي إدراك الخطر الصحي والثعور بالديؤولية من إعداد الباحثان. توصلت الدراسة إلى النتائج التالية: ارتفاع مستوى إدراك الخطر الصحي لدى الطلاب الوافدين. وجود علاقة ارتباطية طردية ضعيفة بين إدراك الخطر الصحي والثعور بالمسؤولية لاى الطلاب الوافدين. وجود فروق دالة إحصائياً وذات حجم أثر متوسط في مستوى إدراك الخطر الصحي لاى الطلاب الوافدين تبعاً لـتغير النوع. وجود فروق دالة إحصائياً وذات حجم أثر صغير في مستوى إدراك الخطر الصحي تبعاً لمتغير التخصص الدراسي. عدم وجود فروق دالة إحصائياً في مستوى إدراك الخطر الصحي تبعاً لمتغيري العمر والقارة. ختمت الدراسة بعدد من التوصيات وبعض المتترحات لبحوث مستقبلية.

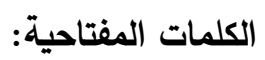

إدراك الخطر ، الدسؤولية، الطلاب الوافدين، جائحة كورونا، COVID-19 


\begin{abstract}
:
This study aimed at revealing the relationship between health risk perception and sense of responsibility among international students at International University of Africa in light of the COVID-19 pandemic, and determining the level of health risk perception and differences according to variables of gender, age, specialization, and continent. The study followed descriptive correlational method. A sample of $(n=149)$ students were selected through purposive sampling. Two scales were designed and used to measure health risk perception and sense of responsibility. The study reached the following results: The level of health risk perception among the international students was high. There was a weak positive correlation between health risk perception and sense of responsibility among the international students. There was statistically significant difference with a medium effect size in level of health risk perception among the international students according to the gender variable. There was statistically significant difference with a small effect size in level of health risk perception according to the specialization variable. There were no statistically significant differences in level of health risk perception according to the variables of age and continent. The study concluded with a number of recommendations and some suggestion for future research.
\end{abstract}

\title{
Keywords:
}

Risk perception, Responsibility, International students, Corona pandemic, COVID-19 
يمثل موضوع الصحة من أهم المواضيع الرئيسية التي حظيت بالكثير من الاهتمام من قبل الباحثن بتخصصاتهم المختلة، وازداد هذا الاهتمام في السنوات الأخيرة نظراً لظهور العديد من الأمراض والأوبئة أملاً في الوصول إلى رعاية صحية

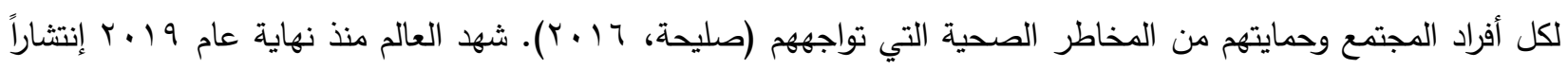
مروعاً لفيروس كورونا الدترتبط بالمتلازمة التتفسية الحادة الثديدة ؟ (SARS-CoV-2) الذي يؤدي إلى مرض فيروس كورونا (COVID-19)

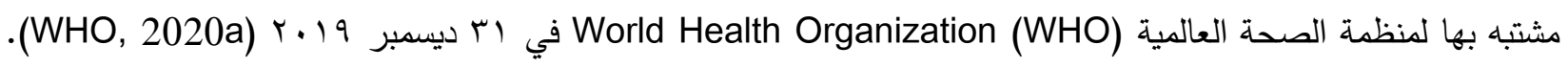

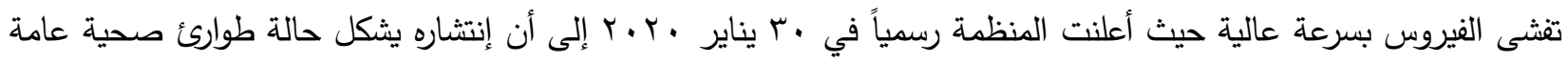

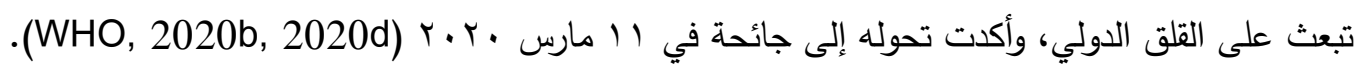

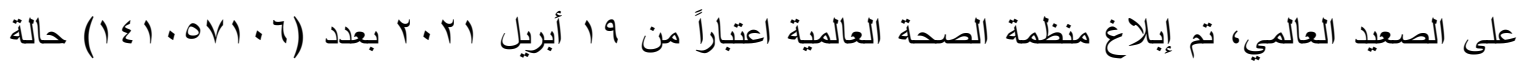

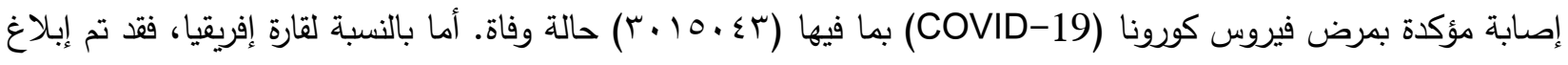

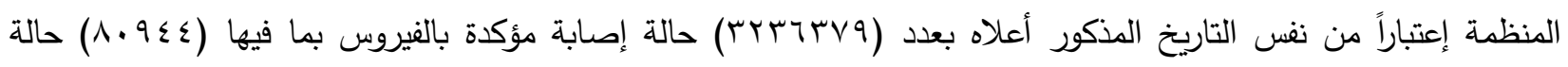

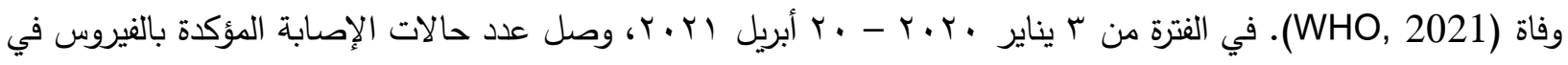
السودان والتي تم إبلاغها لمنظمة الصحة العالمية إلى (r^.rT) حالة بما فيها (T/Y) حالة وفاة، في حين وصلت عدد حالات الإصابة المؤكدة في الصومال والتي تم إبلاغها للمنظمة في نفس الفترة الزمنية إلى (YNYV (107) حالة بما فيها (707) حالة وفاة (WHO, 2020c). مع أنه تم تطوير عدد من اللقاحات لمرض فيروس كورونا (COVID-19) مثل Moderna، \Sputnik V ،Convidecia ،Oxford-AstraZeneca ،Pfizer-BioNTech في توزيعها وتوفيرها - وبالتحديد في قارة إفريقيا - بما فيها ضعف البنية التحتية الصحية وعدم المساواة الاجتماعية والاقتصادية. إضافة إلى ذلك، فإن من الضروري التتبيه بأن أخذ اللقاح وحده غير كافي، حيث يلعب تثكير وسلوك الإنسان دور رئيسي في

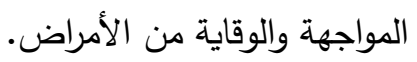


بدأت الحكومات وضع سياسات لإبطاء سرعة انتقال العدوى، إلا أن نجاح مثل تلك السياسات يعتمد جزئياً على امتلاك الجمهور إدراك صحيح ودقيق لعوامل الخطر الثخصية والمجتمعية (Dryhurst et al., 2020). يمكن لسلوك الأفراد أن يوثر ويغير بشكل أساسي على انتشار الأمراض والأوبئة (Bavel et al., 2020).

يشير التميمي (ب99 (1) بأن مسؤولية الفرد الاجتماعية تقع في دوائر تتسع تدريجياً من مسؤوليته إزاء نفسه، ثم مسؤوليته عن أسرته، ثم جيرانه، ثم مجتمعه المحلي، ثم أخيراً إزاء الإنسانيه كلها. لذا يعتبر الثعور بالمسؤولية محك مهم للطلاب وبالتحديد في مثل هذه الأوقات التي يمر بها العالم من تفشي وباء يهدد صحة وسلامة الفرد والمجتمع على حد سواء.

أثرت الجائحة جميع جوانب الحياة اليومية بما فيها العملية التعليمية والأكاديمية، حيث تم تعليق الأنشطة الأكاديمية في الجامعات مما أحدث تغيرات مفاجئة في طبيعة حياة الطلاب وأنشطتهم الصفية واللاصفية. إضافة إلى ذلك فإن عدد كبير من الطلاب الوافدين بجامعة إفريقيا العالمية يعيشون في السكن الجامعي أو الداخليات الخاصة وأصبحوا غير قادرين إلى الرجوع إلى بلدانهم نتيجة للقيود المفروضة على السفر . ما يعني ذلك هو أنهم يعيشون معاً وبأعداد كبيرة في الداخليات، كما أنهج يخرجون لشراء الأشياء الضرورية. كل هذا يشكل خطراً على أنفهم والمجتمع، ويُظهر الحاجة الماسة إلى ممارسة السلوك المسؤول. يلعب إدرالك الأفراد وسلوكهم دوراً رئيسياً في نشأة الأمراض وتطورها، وجهلهم للعلاقة بين المشكلات الصحية من جهة ونمط تفكيرهم وسلوكهم من جهة أخرى يمكن أن يعرضهم لهخاطر صحية (صليحة، 7 (ب). يعرف ستيرنبرغ وستيرنبرغ (Sternberg \& Sternberg, 2012) إلى تمثيلات عقلية من خلال فهمها وتتظيمها وتحديد المعاني الخاصة بها. يمكن تعريف الخطر على أنه احتمال الوقوع أو التعرض لحدث مؤذي وشدة الإصابة أو المرض الناجم عنه (Renner \& Schupp, 2011). تثير داركر (Darker, 2013) بأن إدراك الخطر هو تقييم معرفي للضرر أو الخسارة المحتملة ويمثل حكم ذاتي يصدره الفرد حول خصائص وشدة الخطر • يمثل إدراك الخطر الصحي استجابة وتقييم معرفي للخطر الناتج عن الأمراض (Ferrer \& Klein, 2015).

بدأت البحوث النفسية حول إدراك الخطر كدراسات تجريبية لتقييم الاحتمالات، تقييم المنفعة، وعمليات اتخاذ القرار (Edwards, 1961). يتمثل التطور الرئيسي في هذا المجال اكتثاف مجموعة من الاستراتيجيات الذهنية (Kahneman et al., التي يستخدما الناس لفهم عالم غير مؤكد (Heuristics) أو الاستدلال (Mental Strategies) (1982. تثير نظريات السلوك والتواصل الصحي التطبيقي بأن إدراك الأفراد للخطر الصحي يؤثر على سلوكهم في المخاطرة 
أو التجنب عن مصادر الخطر حفاظاً على سلامتهم وسلامة المجتمع (Gaube et al., 2019). من الضروري مراعاة أبعاد إدراك الخطر وذلك لفهم كيفية تأثيره على السلوك. تظظر معظم النماذج الحالية للسلوك الصحي إلى إدرالك الخطر على أنه بناء معرفي يتكون من مكونين فقط: الاحتمال المدرك (Perceived likelihood) والثدة المدركة (Perceived severity). الاحتمال الدرك هو احتمال يحدده الفرد ذاتياً ويرتبط بحدوث نتيجة سلبية تتعلق بسلوكه، بينما تمثل الثدة المدركة الدرجة المفترضة للضرر الناشئ عن النتيجة السلبية لسلوك الفرد (Brewer et al., 2007).

يشير دينغ وريتثي (2018) بأن فهم كيفية اختلاف إدراك الخطر بناءاً على اختلاف المجموعات أمر مهم للغاية ويمكن أن يساعد في تطوير تواصل أكثر استهدافاً لتغيير إدارك الخطر ـ هنالك العديد من العوامل التي تؤدي إلى ظهور فروق فردية وجماعية في إدراك الخطر • تؤدي كلا من الثخصية، مستوى الكفاءة الذاتية، مركز الضبط ، الأسلوب المعرفي، والخبرة إلى ظهور فروق فردية في إدراك الخطر، بينما تظهر الفروق الجماعية نتيجة لعوامل مثل الجنسية، الثقافة، والخصائص الديمغرافية الاجتماعية (أنظر مراجعة Breakwell, 2014 يمثل إدراك الخطر الصحي بداية ضرورية لظهور الدافعية في تغيير السلوك؛ إلا أن هنالك حاجة إلى توظيف موارد التتظيم الذاتي مثل الكفاءة الذاتية والتخطيط لتغيير السلوكيات المعدة بنجاح (Renner \& Schupp, 2011).لا ينشأ معظم إدراك الخطر في الحياة اليومية عن إجراء معرفي متعد؛؛ بل من خلال عمليات تلقائية وبديهية. تتمثل إحدى سمات هذه العمليات في أنها تتأثر جداً بالمشاعر ، والتي تمثل طريقة سريعة وفعالة (Slovic \& Peters, للغاية في استخدام الموارد لإصدار الأحكام والقرارات في المواقف المعقدة والتي يحتمل أن تكون خطرة $.2006)$

أظهرت العديد من الدراسات أنه عندما يطلب من الأثخاص تتييم احتمال الإصابة بمرض معين أو التعرض لحوادث

أو مشاكل أخرى، فإن معظهم يفيدون بأن المخاطر التي يمكن أن تصيبهم أقل من المتوسط (أنظر مراجعة Helweg-Larsen) Shepperd, 2001 \&. يشير هذا الاعتقاد بأن الناس يقللون من تقديرهم لمخاطرهم الثخصية، الأمر الذي يدل إلى وجود انحياز معرفي يعرف بانحياز التفاؤل (Optimism bias) (Sharot, 2011; Weinstein, 1980). تشير رينر وشوب (أنه حتى عندما يكون الخطر الصحي على المجتمع مفهوم بشكل جيد، فإن ذلك لا يعني أن الأفراد يعتقدون أنهم معرضون شخصياً للخطر ـ يشير الباحثان بأن طريقة التفكير هذه قد تظهر عند طلاب المرحلة الجامعية 
نسبة لبعض خصائهم مثل العمر ومستوى صحتهم الجيدة نسبياً، حيث يمكن أن يكون عندهم حكم وتقدير متحيز حول احتمال وشدة الإصابة بمرض فيروس كورونا (COVID-19).

يرى الباحثان بأنه يمكن أن تظهر بعض المشاكل في التعامل مع المعلومات وذلك نسبة لكثرة مصادرها المتاحة للطلاب وبالتحديد عبر وسائل التواصل الاجتماعي، حيث تؤثر تلك المعلومات إدراكهم وانفعالهم وسلوكهم تجاه الخطر الصحي، مع العلم بأن جزء كبير منها غير موثق بصورة دقيقة وقد لا يكون مبني بأدلة علمية، إضافة إلى المعلومات الكاذبة والمضللة التي يتم نشرها بصورة متعدة. كل هذا يظهر الحاجة إلى اكتساب الطلاب لمهارات معرفية تساعدهم في انتقاء المعلومات الصحيحة من الكم الهائل المتاح في شبكة المعلومات.

يمثل احساس الفرد بالمسؤولية تجاه مجتمعه ركن أساسي في حياته والمجتمع. يشير كورليت (Corlett, 2013) بأن مصطلح المسؤولية معقد وله استخدامات مختلفة في القانون، الفلسفة والعلوم الاجتماعية. تمثل المسؤولية قيمة ذات خاصية افتراضية يعززها المجتمع للأفراد عندما يكون بصدد تحديد مدى أخلاقية ما يصدر عنهم من سلوك أو تصرفات، وتتوفر هذه الخاصية لاى الأفراد الذين يتمتعون بقدر من الحرية ولديهم القدرة على الاختيار • يعرف جابر (910 ( المسؤولية على أنها سمة يتصف بها الأفراد القادرون على الاستمرار في أي عمل يكلفون به والذين يمكن الاعتماد علهيم. يشير الثايب (r . . بأن الثعور بالمسؤولية سمة تعبر عن النضج النفسي للفرد بحيث يكون على استعداد للمساهمة في تحقيق مصلحة المجتمع. يذكر إبراهيم (·191 ) إلى أن المسؤولية تفترض وجود فعل يوضع على عاتق شخص ما؛ لأنه هو الذي تسبب في حدوثه، حيث يساءل الثخص عن فعله ويتحمل نتائج تصرفاته مادام هو المسؤول عنه. إن الثخص المتوافق هو الذي يشعر بالمسؤولية شعوراً

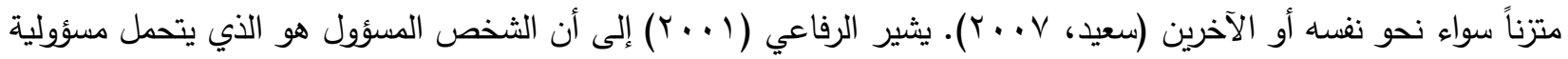
سلوكياته وقراراته ولا يهرب منها بإسقاطه على الآخرين. على الرغم من أن المسؤولية تكوين ذاتي يقوم على نمو الضمير ؛ إلا أن في نموها نتاج اجتماعي يتم تعلمه واكتسابه. تبدأ عملية تعلم الشعور بالمسؤولية منذ مرحلة الطفولة وتتمو تدريجياً عن طريق التربية والتنشئة (برقاوي، 1 . . r).

يمثل كلاً من الاهتمام والفهم والمشاركة عناصر رئيسية للشعور بالمسؤولية. تتضمن مسؤولية الاهتمام الارتباط العاطفي بالجماعة وحرص الفرد على سلامتها وتماسكها وتكاملها واستمراراها وتقدمها وتحقيق أهدافها. تتضمن مسؤولية الفهم استيعاب الفرد للجماعة وللمغزى الاجتماعي لسلوكه. أما مسؤولية المشاركة فيقد بها مشاركة الفرد مع الأخرين في الأعمال التي تخدم 
المجتمع (زهران، . . . ץ). تقسم المسؤلية إلى نوعين، حيث تمثل المسؤولية الخارجية (القانونية) النوع الأول وتتصب على أفعال الفرد الخارجية وهي نوعان: مسؤولية جنائية ومسؤولية مدنية، مع إن هنالك مسؤولية خارجية لا ينظمها القانون وهي المسؤلية الاجتماعية. أما النوع الثاني فهي المسؤولية الداخلية (الأخلاقية) والتي تعبر عن إحساس الفرد بنتائج أفعاله الحرة ومحاسبته لنفسه (إبراهيم، • 91 ()). وذكر زهران ( . . ب) بأن للمسؤولية ثلاث مستويات مترابطة ومتكاملة، المستوى الأول: المسؤولية الفردية (الذاتية)، وهي مسؤولية الفرد عن نفسه وعن عمله. المستوى الثاني: المسؤولية الاجتماعية، وهي مسؤولية الفرد الذاتية عن الجماعة أمام نفسه والثعور بالواجب الاجتماعي والقدرة على تحمله والقيام به. المستوى الثالث: المسؤولية الجماعية، وهي مسؤولية الجماعة جماعياً وبكاملها عن أعضائها وعن سلوكها، وهذا المستوى يدعم المسؤولية الاجتماعية. إن عدم الثعور بالمسؤولية قد يشكل خطراً على بناء المجتمع، بينما الثعور بها وتحمل نتائجها يحقق للإنسان التكيف النفسي والاجتماعي وتخطي الصعاب التي قد تعترض طريقه (اللحياني، (1 (ب). تمثل المسؤولية شكل من أشكال الوعي الاجتماعي الذي يجسده الفرد في تفكيره وتصرفاته وعلاقاته مع الآخرين حيث يفضل الفرد المصلحة الجماعية على المصلحة الذاتية، مما يسهم في التخلي عن النوازع الذاتية والأنانية والعمل من أجل الصالح العام (الخراشي، ؟ . . ؟). يشير بالباحثان بأن شعور الطلاب بالمسؤولية وتتازلهم عن ممارسة بعض السلوكيات المرغوبة لديهم في فترة ينتشر فيها الوباء قد يدل على وعيهم الاجتماعي وفهمه بأنه يمكن أن يكون لسلوك الفرد تأثير كبير على المجتمع. منذ ظهور مرض فيروس كورونا (COVID-19)، تم إجراء عدد من الدراسات التي تتاولت إدرالك الخطر الصحى والثعور بالمسؤولية لدى طلاب المرحلة الجامعية. هدفت دراسة دينغ وآخرون (Ding et al., 2020) إلى معرفة مستوى إدراك خطر COVID-19 لدى طلاب المرحلة الجامعية في الصين خلال فترة الحجر الصحي. استخدم الدراسة التصميم المقطعي العرضي، وتم نشر استبيان عبر WeChat و (خدمات تواصل اجتماعي تستخدم في الصين) حيث تم جمع البيانات من COVID-19 ط = 1461) لدى الطلاب. وجدت الدراسة أيضاً بأن إدراك الخطر يرتفع بلجة عالية وسط الطالبات، طلاب التخصصات غير الطبية، الطلاب الذين تقع جامعاتهم في مقاطعة هوبي، والطلاب ذوي المستوى المعرفي العالي. أجرى تغرير وآخرون (Taghrir et al., 2020) دراسة مقطعية عرضية هدفت إلى الكثف عن المعرفة والسلوكيات الوقائية وإدراك الخطر المرتبط بمرض COVID-19 لدى طلاب الطب بجامعة شيراز للعلوم الطبية في إيران. بلغ حجم العينة (n = 240) طالباً. أظهرت نتائج الدراسة إلى ارتفاع مستوى 
المعرفة وممارسة السلوكيات الوقائية واعتدال مستوى إدراك الخطر لدى الطلاب. وجدت الدراسة انخفاض مستوى إدراك الخطر لإى الإناث والعاملين في قسم الطوارئ مقارنة بالذكور والعاملين في الأقسام الأخرى. بينما هدفت دراسة سلطان وزملائها Soltan) et al., 2020) الطب بجامعة قناة السويس في مصر (n=283 n). كثفت الدراسة إلى ارتفاع مستوى المعرفة وإدراك الخطر والسلوكيات المرتبطة بالمرض. وجدت الدراسة علاقة ارتباطية طردية متوسطة بين المعرفة المرتبطة بالمرض وممارسة التدابير الوقائية. وجدت الدراسة أيضاً بأن إدراك الخطر يرتبط بممارسة التدابير الوقائية. أشارت النتائج وجود فروق في الممارسات الوقائية لصالح الإناث وطلاب السنة الأخيرة.

قام تاديسي وآخرون (Tadese et al., 2021) بدراسة مستعرضة لمعرفة إدراك خطر COVID-19 لدى طلاب جامعة ديبري برهان في إثيوبيا خلال إعادة فتحها. تم جمع البيانات من عينة تمثل جميع طلاب الجامعة (n = 682). أشارت نتائج الدراسة انخفاض مستوى إدراك خطر COVID-19 لدى الطلاب في وقت استئناف الدراسة. أظهرت النتائج بأن كلاً من العمر، الحالة الاجتماعية، مستوى تعليم الوالدين، الإصابة بمرض السكري، استخدام وسائل التواصل الاجتماعي، ومصادر المعلومات تمثل عوامل محددة في إدراك خطر المرض. أما دراسة أحمد وآخرون (Ahmad et al., 2021) فقد هدفت إلى استقصاء إدرالك خطر COVID-19 لدى طلاب الطب الوافدين في الصين ورغبتهم للعودة إلى بلدانهم (n = n). أظهرت نتائج الدراسة انخفاض مستوى إدراك الخطر للى الطلاب بسبب الإجراءات الوقائية التي اتخذتها الصين ضد المرض. كثفت النتائج استعداد الطلاب للبقاء في الصين حتى الإنتهاء من دراستهم • بينما كان الطلاب الذين أكملوا الدراسة على استعداد للعودة إلى بلدانهم في أقرب وقت ممكن. قام هان وآخرون (Han et al., 2021) بدراسة لمعرفة علاقة إدراك خطر PsyCorona(") بالانفعالات والصحة النفسية. قامت الدراسة بتحليل بيانات مقطعية وطولية من مسح شملت التي

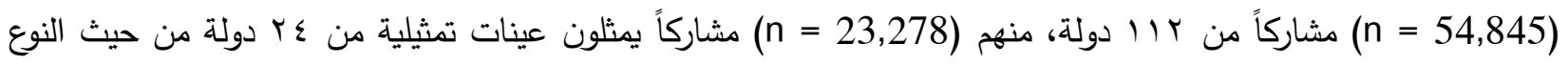
والعمر ـ أشارت نتائج الدراسة إلى ارتباط الإدراك العالي لخطر COVID-19 بزيادة الانفعالات السلبية. كما أظهرت النتائج وجود علاقة ارتباطية عكسية بين إدرالك الخطر والصحة النفسية. هدفت دراسة رانا وآخرون (Rana et al., 2021) إلى معرفة الفروق في النوع في إدراك خطر COVID-19 وآليات التأقلم. بلغ حجم العينة (n = 379) مشاركاً في الباكستان. أظهرت نتائج الدراسة https://psycorona.org مشروع متعدد البلدان يهدف إلى تحديد العوامل النفسية والثقافية التي تؤثر على انتشار COVID-19. PsyCorona (*) 
إلى ارتفاع مستوى إدراك الخطر لاى الإناث مقارنة بالذكور ـ أظهرت النتائج أيضاً بأن الإناث أكثر قدرة في التبني بآليات التأقلم مقارنة بالذكور. أما دراسة رودريغيز بيستيرو (Rodriguez-Besteiro et al., 2021) فقد هدفت إلى معرفة الفروق في النوع لاى طلاب المرحلة الجامعة في إدراكهم لخطر COVID-19 وسلوكهم الغذائي ونشاطهم البدني. وصل حجم العنية (n = 300) طالباً في إسبانيا. أظهرت النتائج ارتقاع مستوى إدراك خطر COVID-19 عند الإناث مقارنة بالذكور ، لكن لم تظهر أي فروق في كيفية تأثير الوباء على الحياة الثخصية. كثفت النتائج زيادة استهلاك المشروبات الغازية عند الذكور مقارنة بالإناث. لم تظهر أي فروق في ممارسة النشاط البدني. قام سينغكون وآخرون (Singkun et al., 2020) بدراسة لمعرفة سلوكيات المسؤولية الاجتماعية والعوامل المرتبطة بها لدى طلاب المرحلة الجامعية في ب جامعات في التايلاند (n = n16). أظهرت نتائج الدراسة إلى ارتفاع المسؤولية الاجتماعية لدى الطلاب للوقاية من COVID-19. كثفت النتائج وجود علاقة ارتباطية طردية بين سلوكيات المسؤولية الاجتماعية لدى الطلاب ومعرفتهم حول انتقال وخطر الفيروس وأيضاً اتجاهاتهم نحو التدابير التي تتذذها الدولة للوقاية من COVID-19. أما الدراسة الوصفية التي أجراها سيفرينو غونزاليس وزملاؤ al., 2020) فقد هدفت إلى استقصاء المسؤولية الاجتماعية لاى طلاب المرحلة الجامعية في دولتي تثيلي والسلفادور (n = 288). أظهرت نتائج الدراسة إلى ارتفاع المسؤولية الاجتماعية لدى الطلاب. كثفت النتائج وجود فروق في مستوى الثعور بالمسؤولية الاجتماعية لصالح الطلاب في تثيلي والذين جاءوا من المناطق الريفية.

من خلال استعراض الدراسات السابقة يمن الخروج بخلاصة هي ارتفاع مستوى إدراك خطر بالمسؤلية لاى طلاب المرحلة الجامعية. بالنسبة للفروق بين الذكور والإناث في إدراك الخطر الصحي، أظهرت نتائج بعض الدراسات فروق لصالح الذكور في حين كثفت الدراسات الأخرى فروق لصالح الإناث. مع أن إدراك الخطر أمر ضروري للتجنب من الإصابة بالمرض وتقليل درجة انتقاله؛ إلا أن ذلك يرتبط بزيادة في الإنععالات السلبية التي قد تؤدي إلى مشاكل في الصحة النفسية. تثير نتائج الدراسات بأن وسائل الإعلام والتواصل الاجتماعي تلعب دور في إدراك الخطر. أشارت الدراسات بأن الإجراءات الوقائية التي تتذذها الحكومات والمؤسسات قد تؤثر في مستوى إدراك الخطر والثشعور بالمسؤولية. 
يمثل الطلاب الوافدين بالمرحلة الجامعية مجموعة ديناميكية تتمتع بدرجة عالية من الحركة والتتقل والنشاط الاجتماعي، وغالباً ما تكون لديهم أعرض خفيفة بعد الإصابة بمرض فيروس كورونا (COVID-19) نسبة لكونهم شباب يتمتعون بصحة جيدة نسبياً. هذه العوامل يمكن أن تلعب دور في مستوى إدراكهم للخطر الصحي للفيروس، مما قد يكون له تأثير كبير على إنتثاره. في مثل هذه الأوقات التي نمر بها، تظهر الحاجة إلى ممارسة السلوك المسؤول بصورة ملحة، لذلك من الضروري دراسة إدراك الخطر الصحي والثعور بالمسؤلية لاى طلاب المرحلة الجامعية. في ضوء ما تقدم يكن بلورة مشكلة الدراسة الحالية في محاولة الإجابة عن الأسئلة الآتية:

1. ما مستوى إدراك الخطر الصحي لدى الطلاب الوافدين بجامعة إفريقيا العالمية؟

r. هل توجد علاقة ارتباطية بين إدراك الخطر الصحي والثشعور بالمسؤولية لاى الطلاب الوافدين بجامعة إفريقيا العالمية؟ r. هل توجد فروق في مستوى إدراك الخطر الصحي لاى الطلاب الوافدين بجامعة إفريقيا العالمية تبعاً لمتغير النوع؟ ؟. هل توجد فروق في مستوى إدراك الخطر الصحي لاى الطلاب الوافدين بجامعة إفريقيا العالمية تبعاً لمتغير العمر؟ ه. هل توجد فروق في مستوى إدراك الخطر الصحي لاى الطلاب الوافدين بجامعة إفريقيا العالمية تبعاً لتتغير التخصص

$$
\text { الدراسي؟ }
$$

T. هل توجد فروق في مستوى إدراك الخطر الصحي لاى الطلاب الوافدين بجامعة إفريقيا العالمية تبعاً لـتغير القارة؟

\section{أهمية الاراسة:}

تكمن أهمية هذه الدراسة في أنها تسهم في سد الفجوة البحثية في دراسات إدراك الخطر الصحي والثشعور بالمسؤولية للى الطلاب الذين يمثلون فئة حيوية يلعب سلوكها دوراً مهماً في صحة وسلامة المجتمع. تمثل هذه الدراسة أول دراسة أجريت على الطلاب الوافدين في الجامعات السودانية أثناء جائحة COVID-19، وذلك حسب علم الباحثان. للدراسة أهية نفسية واجتماعية، كونها ترصد مرحلة في حياة الطلاب الوافدين بجامعة إفريقيا العالمية، في مواجهة جائحة أثرت جميع مناحي الحياة، وذلك من خلال الربط بين نشاطهم الإدراكي المعرفي وممارسة سلوكهم اليومي بصورة مسؤولة. يمكن أن تزود نتائج هذه الدراسة المؤسسات الأكاديمية بمعلومات تساعدهم في تطوير برامج تثقيفية للطلاب حول إدراك الخطر الصحي والثعور بالمسؤلية. 
يمكن أن تساعد هذه الدراسة المهتمين بمجال الصحة العامة في الانتباه إلى ضرورة مراعاة دور النشاط المعرفي في السلوك أثناء تفثي الأمراض والوبائيات. يمكن أن تساعد الدراسة الجهات الإعلامية في إعداد حملات تستهدف الثباب والطلاب لرفع وعيهم حول المخاطر الصحية. أهداف الدراسةة:

$$
\text { تمثلت أهداف الدراسة في الآتي: }
$$

ا ـ التعرف على مستوى إدراك الخطر الصحي لدى الطلاب الوافدين بجامعة إفريقيا العالمية. r. الكثف عن العلاقة الارتباطية بين إدراك الخطر الصحي والثعور بالميؤولية لدى الطلاب الوافدين بجامعة إفريقيا

$$
\text { العالمية. }
$$

r. إبراز الفروق في مستوى إدراك الخطر الصحي لدى الطلاب الوافدين بجامعة إفريقيا العالمية تبعاً لمتغير النوع. ع. التعرف على الفروق في مستوى إدراك الخطر الصحي لدى الطلاب الوافدين بجامعة إفريقيا العالمية تبعاً لمتغير العمر . ه. الكثف عن الفروق في مستوى إدراك الخطر الصحي للى الطلاب الوافدين بجامعة إفريقيا العالمية تبعاً لمتغير التخصص الاراسي. T. إظهار الفروق في مستوى إدراك الخطر الصحي لدى الطلاب الوافدين بجامعة إفريقيا العالمية تبعاً لمتغير القارة.

ا. يتسم مستوى إدراك الخطر الصحي لدى الطلاب الوافدين بجامعة إفريقيا العالمية بالإرتفاع. r. توجد علاقة ارتباطية بين إدراك الخطر الصحي والثعور بالمسؤولية لدى الطلاب الوافدين بجامعة إفريقيا العالمية. r. توجد فروق في مستوى إدراك الخطر الصحي لدى الطلاب الوافدين بجامعة إفريقيا العالمية تبعاً لمتغير النوع. ع. توجد فروق في مستوى إدراك الخطر الصحي لدى الطلاب الوافدين بجامعة إفريقيا العالمية تبعاً لمتغير العمر. ه. توجد فروق في مستوى إدراك الخطر الصحي لدى الطلاب الوافدين بجامعة إفريقيا العالمية تبعاً لمتغير التخصص الدراسي. 
7. توجد فروق في مستوى إدراك الخطر الصحي لدى الطلاب الوافدين بجامعة إفريقيا العالمية تبعاً لمتغير القارة.

مصطلحات الدراسة والتعريفات الإجرائية:

أولاً: إدراك الخطر:

تعرف داركر (Darker, 2013) إدراك الخطر بأنه تقييم معرفي للضرر أو الخسارة المحتملة ويمثل حكم ذاتي يصدره

الفرد حول خصائص وشدة الخطر • يعرف الباحثان إدراك الخطر الصحي إجرائياً بالدرجات التي يتحصل عليها المفحوص بعد

تطبيق مقياس إدراك الخطر الصحي عليه.

ثانياً: الشعور بالمسؤولية:

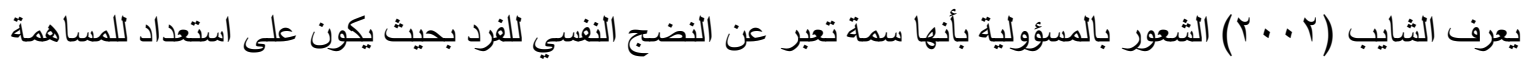

في تحقيق مصلحة المجتمع. يعرف الباحثان الثعور بالمسؤولية إجرائياً بالدرجات التي يتحصل عليها المفحوص بعد تطبيق مقياس الثعور بالمسؤولية عليه.

حدود الدراسة:

تقتصر عينة الدراسة على الطلاب الوافدين بمرحلة البكالوريوس في جامعة إفريقيا العالمية، حيث تم جمع البيانات في الفترة من

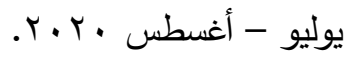

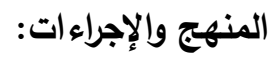

المنهج:

تم استخدام المنهج الوصفي الارتباطي وبالتحديد التصميم الارتباطي المقطعي العرضي باعتباره الأكثر ملاعمة للإجابة عن أسئلة الدراسة الحالية. 


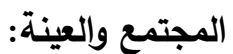

تكون مجتمع الدراسة من جميع الطلاب الوافدين بمرحلة البكالوريوس في جامعة إفريقيا العالمية والبالغ عددهم حوالي

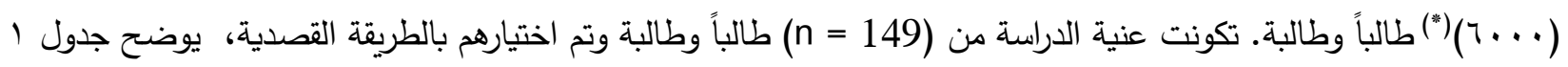
توزيع العينة حسب المتغيرات الديمغرافية التالية: النوع، العمر ، التخصص الدراسي، والقارة.

$$
\text { جدول 1: توزيع العينة حسب المتغيرات الديمغرافية (n = 149) }
$$

\begin{tabular}{|c|c|c|c|}
\hline النسبة (\%) & التكرار & & المتغير \\
\hline$V Y, Y$ & 110 & ذكور & \multirow[t]{2}{*}{ النوع } \\
\hline$r, \Lambda$ & $r \varepsilon$ & إناث & \\
\hline $0 ৭, \vee$ & 19 & 11 - & \multirow{2}{*}{ العمر (") } \\
\hline$\varepsilon \cdot, r$ & 7. & 0r عاماً فما فوق & \\
\hline$r \cdot, r$ & «o & علوم صحية & التخصص \\
\hline $79, \wedge$ & $1 . \varepsilon$ & أخرى & الدراسي \\
\hline$V \wedge, 0$ & $11 \mathrm{~V}$ & إفريقيا(() & \multirow[t]{2}{*}{ القارة } \\
\hline r1,0 & re & آسيا(ب) & \\
\hline & & لانحراف المعياري): & (") متوسط \\
\hline
\end{tabular}

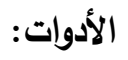

قام الباحثان بتصميم مقياسين لقياس إدراك الخطر الصحي والثعور بالمسؤولية. 


\section{أولاً: مقياس إدراك الخطر الصحي:}

تكون المقياس في صورته الأولية من (ع () بند، وهو عبارة عن مقياس تقدير ذاتي يتضمن ثلاث مستويات للاستجابة

هي: (أوافق = r درجات، غير متأكد = درجتان، لا أوافق = درجة واحدة)، وتم عكس التصحيح بالنسبة للبنود السالبة. تم عرض المقياس على (ץ) محكمين للتأكد من سلامة اللغة ومدى ملاءمته للدراسة، وقد أخذ الباحثان مقترحات المحكمين والتي تمثلت في إعادة صياغة بعض البنود وبقي المقياس على بنوده الأصلية (ع () بند. لمعرفة الخصائص السيكومترية لبنود مقياس إدراك الخطر الصحي، قام الباحثان بتطبيق الصورة المحكمة من الsقياس على عينة أولية (n = n) طالباً وطالبة، حيث تم اختيارهم بالطريقة القصدية من مجتمع الدراسة. تم حساب معاملات الارتباط بين درجة كل بند والدرجة الكلية للمقياس، حيث أظهرت النتيجة بأن جميع المعاملات دالة عند مستوى ( ( , ·) وتراوحت بين (190, • - . 79, • ) عدا البند (r () وهو بند سالب الارتباط (-Tr- , • )، لذلك رأى الباحثان أن يحذف حتى لا يؤثر في الثبات. لكعرفة الثبات للارجة الكلية للمقياس في صورته النهائية

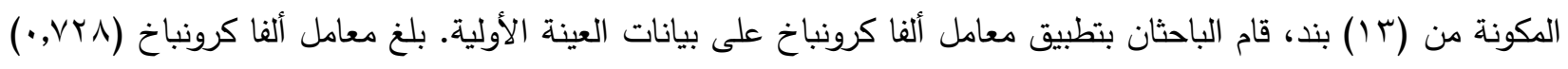

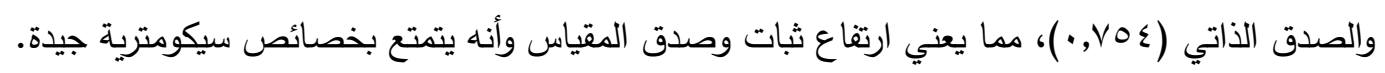

ثانياً: مقياس الثعور بالمسؤولية:

تكون المقياس في صورته الأولية من (r (1) بند، وهو عبارة عن مقياس تقدير ذاتي يتضمن ثلاث مستويات للاستجابة

هي: (أوافق = r درجات، غير متأكد = درجتان، لا أوافق = درجة واحدة)، وتم عكس التصحيح بالنسبة للبنود السالبة. تم عرض المقياس على (ץ) محكمين للتأكد من سلامة اللغة ومدى ملاءمته للدراسة، وقد أخذ الباحثان مقترحات المحكمين والتي تمثلت في إعادة صياغة بعض البنود وبقي المقياس على بنوده الأصلية (r ا ) بند. لمعرفة الخصائص السيكومترية لبنود مقياس الثعور بالمسؤلية، قام الباحثان بتطبيق الصورة المحكمة من المقياس على عينة أولية (30 = n) طالباً وطالبة، حيث تم اختيارهم بالطريقة القصدية من مجتمع الدراسة. تم حساب معاملات الارتباط بين درجة كل بند والدرجة الكلية للمقياس، حيث أظهرت

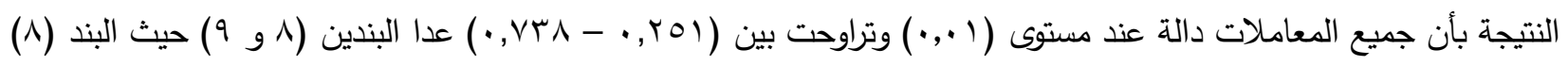
صفري الارتباط ( إ.,.) والبند (9) سالب الارتباط (- (7 , , )، لذلك رأى الباحثان حذفهما حتى لا يؤثرا في الثبات. لكعرفة الثبات للدرجة الكلية للمقياس في صورته النهائية الدكونة من (1') بند، قام الباحثان بتطبيق معامل ألفا كرونباخ على بيانات 


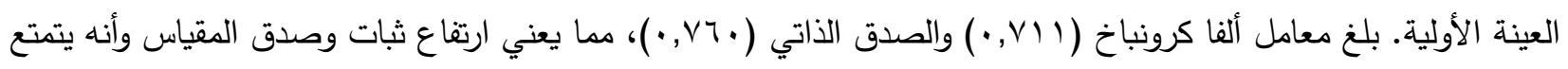
بخصائص سيكومترية جيدة.

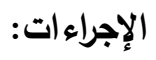

قام الباحثان بنقل الكقياسين مع خطاب الدفحوصين والبيانات الأساسية إلى نماذج غوغل (Google Forms). بعد إنثاء رابط النموذج، تم توزيعه للطلاب باستخدام الواتساب (WhatsApp). تم جمع الاستجابات خلال شهري يوليو وأغسطس

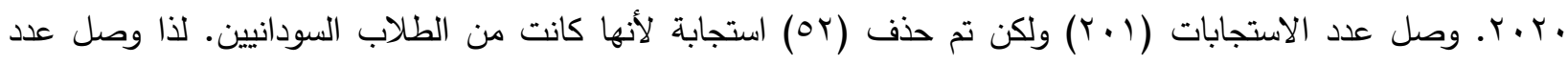
الاستجابات التي تم اعتمادها إلى (9 ()) استجابة من الطلاب الوافدين. تم نقل البيانات من نموذج Google إلى برنامج ومن ثم تم تحويلها إلى برنامج الحزمة الإحصائية للعلوم الاجتماعية (SPSS version.25) ومائم 2013 لمعالجتها. تم استخدام اختبار شابيرو ويلك للتحقق مما إذا كانت البيانات موزعة بشكل طبيعي، حيث أظهرت النتيجة عدم توزعها بصورة طبيعية، ومن ثم تم استخدام التحويل العكسي الطبيعي المبني بالرتب، وأخيراً تم تحليل البيانات ببرنامج الـ(SPSS).

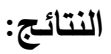

\section{للتحقق من الفرض الأول تم استخدام اختبار (ت) لعينة واحدة، وجدول ؟ يوضح النتيجة.}

جدول r: نتيجة اختبار (ت) لعينة واحدة حول السمة المميزة لمستوى إدراك الخطر الصحي لاى الطلاب الوافدين بجامعة

$$
\text { إفريقيا العالمية (df }=148 \text { ، n = (d49). }
$$

الوسط المحكي الوسط الحسابي

$$
\text { المعياري }
$$

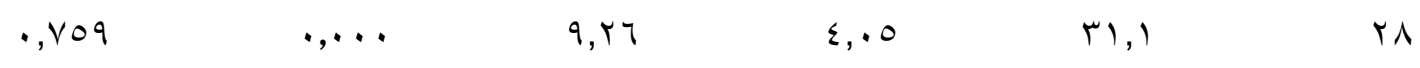

أظهر اختبار (ت) لعنية واحدة في جدول r ارتفاع مستوى إدراك الخطر الصحي لاى الطلاب الوافدين بجامعة إفريقيا

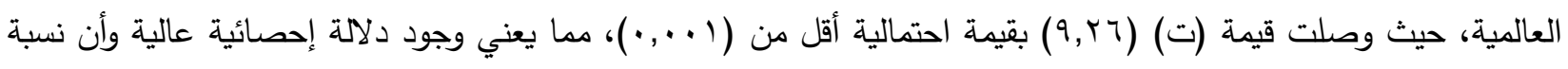
الحصول على هذه النتيجة من خلال الخطأ العشوائي فقط تقل عن (1, •\%\%) إذا كانت الفرضية الصفرية صحيحة. يشير حجم 
الأثر وجود فرق متوسط معياري قدره (V09,·)، مما يعني أن حجم الأثر متوسط وأن لهذه النتيجة دلالة عملية متوسطة بالرغم من الدلالة الإحصائية العالية.

للتحقق من الفرض الثاني تم استخدام معامل ارتباط بيروسون، وجدول ب يوضح النتيجة. جدول r: نتيجة معامل ارتباط بيرسون لمعرفة العلاقة بين إدراك الخطر الصحي والثعور بالسؤولية لاى الطلاب الوافدين بامعة إفريقيا العالمية (n = (n).

\begin{tabular}{|c|c|}
\hline الثعور بالمسؤولية & \\
\hline$* * *, r 9 \varepsilon$ & إدراك الخطر الصحي \\
\hline
\end{tabular}

أظهر معامل ارتباط بيرسون في جدول r وجود علاقة ارتباطية طردية ضعيفة بين إدراك الخطر الصحي والثعور بالمسؤولية لاى الطلاب الوافدين بجامعة إفريقيا العالمية، حيث وصلت قية الارتباط (؟ جr,·) وهي قيمة دالة إحصائيا عند مستوى (1) (., (•).

للتحقق من الفرض الثالث تم استخدام اختبار (ت) لعينتين غير متساويتين، وجدول ؛ يوضح النتيجة. جدول ؛ نتيجة اختبار (ت) لعينتين غير متساويتين حول الفروق في مستوى إدراك الخطر الصحي لاى الطلاب الوافدين

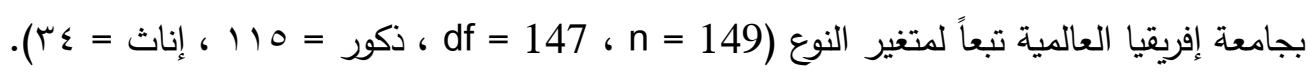
مجموعتي المقارنة

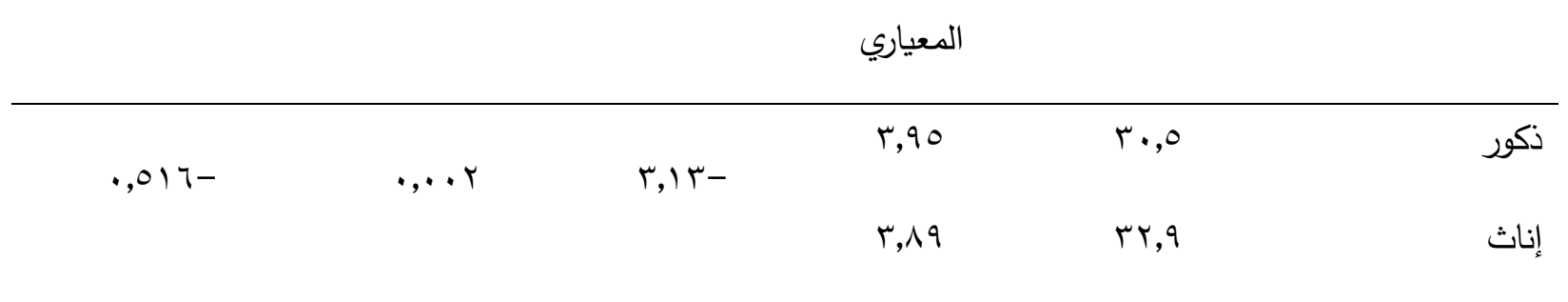

أظهر اختبار (ت) لعينتين غير متساويتين في جدول ؛ وجود فروق دالة إحصائيا في مستوى إدراك الخطر الصحي

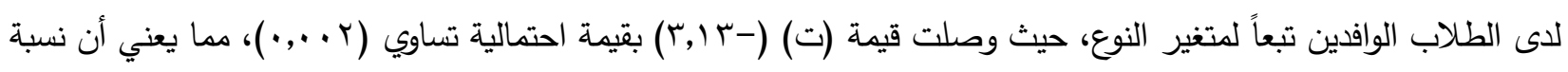
الحصول على هذه النتيجة من خلال الخطأ العشوائي فقط تساوي (ז,. \%) إذا كانت الفرضية الصفرية صحيحة. وبالرجوع إلى 


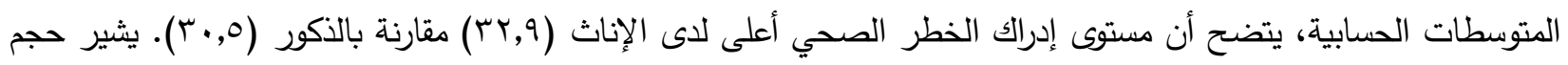
الأثر بأن (7,1\% (1\%) من التباين في مستوى إدراك الخطر الصحي يرجع لمتغير النوع، مما يعني أن الفرق متوسط وأن للنتيجة دلالة عملية متوسطة بالرغم من الدلالة الإحصائية العالية.

\section{للتحقق من الفرض الرابع تم استخدام اختبار (ت) لعينتين غير متساويتين، وجدول • يوضح النتيجة.}

جدول ه: نتيجة اختبار (ت) لعينتين غير متساويتين حول الفروق في مستوى إدراك الخطر الصحي لدى الطلاب الوافدين

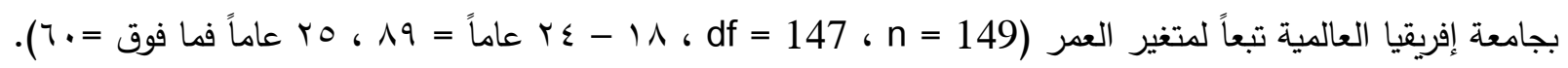

\begin{tabular}{|c|c|c|c|c|}
\hline القيمة الاحتمالية & قيمة (ت) & الانحراف المعياري & الوسط الحسابي & مجموعتي المقارنة \\
\hline .,$Y Y$. & $1, r \mu$ & r,qV & r & 1 | - r عاماً \\
\hline & & $\varepsilon, 17$ & $\Gamma \cdot, \tau$ & هr عاماً فما فوق \\
\hline
\end{tabular}

كثف اختبار (ت) لعينتين غير متساويتين في جدول ه عدم وجود فروق دالة إحصائيا في مستوى إدرالك الخطر الصحي لدى الطلاب الوافدين بجامعة إفريقيا العالمية تبعاً لمتغير العمر، حيث وصلت قيمة (ت) (بr, ( ) بقيمة احتمالية تساوي $\cdot\left(\cdot, Y r^{\prime}\right)$

للتحقق من الفرض الخامس تم استخدام اختبار (ت) لعينتين غير متساويتين، وجدول 7 يوضح النتيجة. جدول \َ: نتيجة اختبار (ت) لعينتين غير متساويتين حول الفروق في مستوى إدراك الخطر الصحي لدى الطلاب الوافدين بجامعة إفريقيا العالمية تبعاً لمتغير التخصص الدراسي (149 = n ، df = 147 ، علوم صحية = 0؛ ، أخرى = ؛ • (). مجموعتي المقارنة

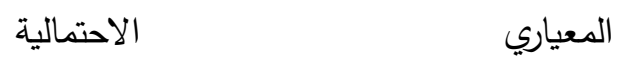

كثف اختبار (ت) لعينتين غير متساويتين في جدول 1 وجود فروق دالة إحصائيا في مستوى إدراك الخطر الصحي

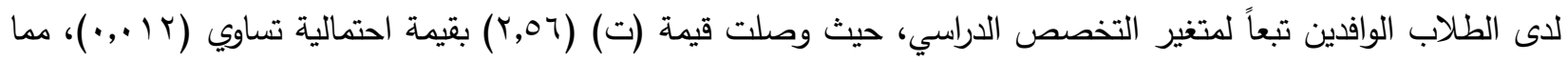


يعني أن نسبة الحصول على هذه النتيجة من خلال الخطأ العشوائي فقط تساوي (r, (\%) إذا كانت الفرضية الصفرية صحيحة. وبالرجوع إلى المتوسطات الحسابية، يتضح أن مستوى إدراك الخطر الصحي أعلى لدى طلاب العلوم الصحية (r,r؟) مقارنة

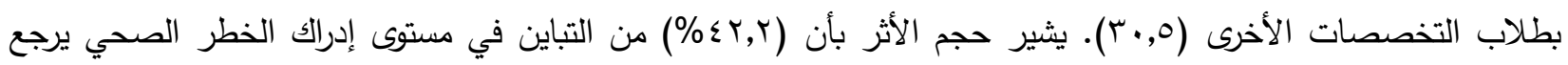
لمتغير التخصص، مما يعني أن الفرق صغير وأن الدلالة العملية للنتيجة منخفضة مقارنة بدلالتها الإحصائية. للتحقق من الفرض السادس تم استخدام اختبار (ت) لعينتين غير متساويتين، وجدول V يوضح النتيجة. جدول V: نتيجة اختبار (ت) لعينتين غير متساويتين حول الفروق في مستوى إدراك الخطر الصحي لدى الطلاب الوافدين

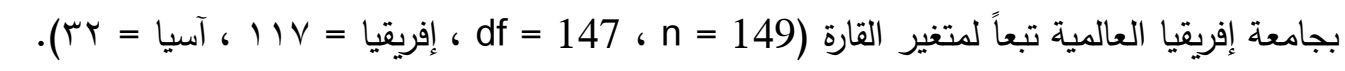

\begin{tabular}{|c|c|c|c|c|}
\hline القيمة الاحتمالية & قيمة (ت) & الانحراف المعياري & الوسط الحسابي & مجموعتي المقارنة \\
\hline.,$+7 V$ & $1, \wedge \leq-$ & $r, 99$ & r., & إفريقيا \\
\hline & & 5,10 & $r, r$ & آسيا \\
\hline
\end{tabular}

أظهر اختبار (ت) لعينتين غير متساويتين في جدول V عدم وجود فروق دالة إحصائيا في مستوى إدراك الخطر الصحي

للى الطلاب الوافدين بجامعة إفريقيا العالمية تبعاً لمتغير القارة، حيث وصلت قيمة (ت) (-ء^, () بقيمة احتمالية تساوي $\cdot(\cdot, \cdot 7 \vee)$

المناقثة:

سعت هذه الدراسة الكثف عن العلاقة بين إدراك الخطر الصحي والثعور بالمسؤولية لدى الطلاب الوافدين بجامعة إفريقيا العالمية في ظل جائحة كورونا (COVID-19)، والتعرف على مستوى إدراك الخطر الصحي لاى الطلاب الوافدين والفروق تبعاً لمتغيرات النوع، العمر، التخصص الدراسي والقارة. أسفرت النتائج إلى وجود علاقة ارتباطية طردية ضعيفة بين إدراك الخطر الصحي والثعور بالمسؤلية. أظهرت النتائج ارتفاع مستوى إدراك الخطر الصحي لدى الطلاب، ووجود فروق في إدراك الخطر الصحي تبعاً للنوع لصالح الإناث والتخصص لصالح العلوم الصحية، وعدم وجود فروق تبعاً للعمر والقارة. يثير الباحثان بأن ارتفاع مستوى إدراك الخطر الصحي لدى الطلاب أثناء انتثار الفيروس يدل على وعيهم ومعرفتهم (Ding et al., حول الفيروس وتتييمه لخطره وعواقبه السلبية. تتفق هذه النتيجة مع دراسات أجريت خلال جائحة كورونا 
COVID-19 2020; Rodriguez-Besteiro et al., 2021; Soltan et al., 2020) لاى طلاب المرحلة الجامعية. مع أهمية إدراك الخطر الصحي ودوره في تغيير السلوك والحد من إنتشار المرض؛ إلا أن ارتغاعه يرتبط بزيادة في الإنفعالات السلبية وحدوث تدهور في الصحة النفسية (Han et al., 2021). قد يتأثر إدراك الخطر الصحي لاى الطلاب بعوامل أكاديمية واجتماعية وسياسية، مثل القرارات التي تصدرها المؤسسات الأكاديمية بثأن تعليق أو مواصلة الدراسة والأنثطة الأكاديمية، والمعلومات التي يتم نشرها في وسائل الإعلام والتواصل الاجتماعي، إضافة إلى السياسات والإجراءات الوقائية التي تتذها الحكومات، حيث أشارت دراسة تاديسي وزملاؤ (Tadese et al., 2021) إلى انخفاض مستوى إدراك خطر COVID-19 للى الطلاب أثناء فترة الرجوع إلى الدراسة وأن لوسائل التواصل الاجتماعي دور في إدراك خطر المرض، كما أثارت نتائج دراسة أحمد وآخرون (Ahmad et al., 2021) إلى انخفاض مستوى إدراك الخطر لاى الطلاب الوافدين في الصين نتيجة للتدابير الوقائية التي اتخذتها الحكومة ضد المرض.

يمكن تقسير العلاقة الطردية بين إدراك الخطر الصحي والثعور بالمسؤولية في أن المعالجة المعرفية لاى الطلاب وفهمهم لخطر الفيروس وتداعياته ترتبط بشعورهم بأن سلوكياتهم تلعب دور رئيسي في إنتشار الفيروس أو الحد منه، وأنهم (Singkun et al., مسؤون تجاه أنفسهم وزملائهم والمجتمع الذي يعيشون فيه. تتفق هذه النتيجة مع دراسة سينغكون وآخرون (2020 والتي أظهرت وجود علاقة ارتباطية طردية بين سلوكيات المسؤلية الاجتماعية لدى الطلاب ومعرفتهم حول خطر الفيروس. يشير الباحثان بأن ممارسة السلوك المسؤول أمر في غاية الأهمية عندما يكون السلوك ذات أثر مباشر وكبير على صحة وسلامة الفرد والمجتمع، حيث تمثل الفترة التي يمر بها العالم الآن فترة تظهر مدى النضج النفسي والاجتماعي لاى الطلاب وتتقديرهم للنتائج المحتملة لسلوكياتهم.

تثير مارتاريلّي وولف (Martarelli \& Wolff, 2020) بأن الملل وضبط الذات عاملان رئيسيان لفهم التحديات التي تفرضها تدابير احتواء جائحة كورونا (COVID-19) على الأفراد، حيث يؤثر الثعور بالملل على السلوك، بينما يتطلب ضبط الذات إلى بذل المزيد من الجها المعرفي. يرى الباحثان بأنه نسبة للأنشطة الأكاديمية والاجتماعية والرياضية التي اعتادوا عليها الطلاب بممارستها والتي تم إيقافها لمنع إنتشار الفيروس؛ قد يظهر الثعور بالملل والحاجة إلى مزيد من ضبط الذات. وبسبب الفروق الفردية واختلاف سمات الثخصية، فقد لا ينجح بعض الطلاب في مواجهة الملل وتحكم الذات مما قد يؤدي إلى قيامهم بسلوكيات غير مسؤولة مع علمهم بالأخطار الصحية التي تنتج عنها، ويمكن أن يكون هذا سبب ضعف العلاقة الطردية بين 
إدراك الخطر الصحي والشعور بالمسؤولية التي وجدتها الدراسة الحالية. أظهرت الدراسة وجود فروق في إدراك الخطر الصحي لفيروس كورونا لدى الطلاب الوافدين تبعاً لمتغير النوع لصالح الإناث. تتقق هذه النتيجة مع نتائج عدد من الدراسات والتي كثفت (Ding et al., 2020; Rana et al., 2021; Rodriguez-Besteiro وجود فروق في إدراك خطر الفيروس لصالح الإناث (Taghrir et al., 2020) والتي أظهرت فروق لصالح الذكور • et al., 2021) بالرغم من أن النتيجة كثفت فروق دالة إحصائيا في إدراك الخطر الصحي لصالح الإناث؛ إلا أن حجم الأثر متوسط مما يشير إلى عدم وجود فروق كبيرة وذات أهمية عملية عالية بين الذكور والإناث في فهمه وتقييمهم للخطر الصحي لمرض فيروس كورونا.

يثير الباحثان بأن المجال الأكاديمي الذي يدرسه الطالب يمكن أن يلعب دور في إدراكه للخطر الصحي، وقد يفر ذلك النتيجة التي توصلت إليها الدراسة في ارتفاع مستوى إدراك الخطر الصحي لجائحة 19-COVID عند طلاب التخصصات الصحية مقارنة بطلاب التخصصات الأخرى. تختلف هذه النتيجة مع دراسة دينغ وآخرون (Ding et al., 2020) والتي كثفت ارتفاع مستوى إدراك خطر الجائحة وسط طلاب التخصصات غير الطبية. أظهرت الدراسة الحالية إلى وجود حجم أثر صغير للفروق في إدراك الخطر الصحي لدى الطلاب تبعاً للتخص. يرجع الباحثان عدم وجود الفروق في إدراك الخطر الصحي لدى الطلاب تبعاً لمتغير العمر إلى التقارب العمري فيما بينه، حيث نجد أغلبية الطلاب في مرحلة الثباب. فالتقارب العمري قد يلعب دور في حجم خبراتهم السابقة المرتبطة بالأمراض إضافة إلى قوة مناعتهم وتمتعهم بصحة جيدة نسبياً. أثارت دراسة نينو وآخرون (Niño et al., 2021) الحالية فروق في إدراك الخطر الصحي لدى الطلاب الوافدين تبعاً للقارة، حيث لم تكن هنالك فروق بين الطلاب الأفارقة والآسيويين. قد يرجع ذلك إلى تثابه فهمه لخطر المرض نتيجة لتقارب المعلومات التي يقومون باستقبالها ومعالجتها، مع وجود الاختلافات في الجنسية، اللغة، والثقافة.

ينبغي ذكر عدد من الحدود التي تقيد قابلية نتائج الدراسة الحالية للتعميم. أولاً، عينة الدراسة غير احتمالية ولا تمثل المجتمع. ثانياً، تم استخدام مقاييس التقرير الذاتي التي لا تخلوا من تحيز استجابات المفحوصين المرتبط بالمقبولية الاجتماعية. وأخيراً، تم استخدام المنهج الارتباطي وبيانات مقطعية عرضية مما يعني أنه لا يمكن الوصول إلى استتتاج سببي عن نتائج 
تمثل جائحة كورونا مثالاً واضحاً في قدرة الأوبئة على تعطيل جميع جوانب الحياة اليومية، ناهيك عن الوفيات الهائلة

الناجمة عنها. يلعب سلوك الأفراد ونشاطهم المعرفي دور هام في مواجهة الأزمات التي تواجه المجتمع. تؤكد هذه الدراسة دور إدراك الخطر الصحي وممارسة السلوك المسؤول عند الطلاب الجامعيين - كفئة حيوية في المجتمع - في السيطرة على إنتشار الأمراض وتخفيف التداعيات الناجمة عنها • بناءاً على نتائج الدراسة يوصي الباحثان بالآتي: على الجامعات والمؤسسات الأكاديمية وبالتحديد عمادات شؤون الطلاب ووحدات إشراف السكن الجامعي تطوير برامج تثقيفية صحية تتشر الوعي الصحي وسط الطلاب، كما ينبغي المشاركة في تطويرها من قبل الأكاديميين والممارسين المهنيين في تخصصات الطب والصحة العامة وعلم النفس وعلم الاجتماع. ينبغي أن تتخذ جهات صنع السياسات قرارات مبنية بأدلة علمية للتغلب من الصعوبات التي تواجه الطلاب نتيجة لتفشي الجائحة. ضرورة إعداد وتقديم حملات إعلامية تستهدف الشباب والطلاب لرفع وعيهم وتغيير السلوكيات السالبة التي يمكن أن يقوموا بها، كما يجب تدريبهم بالاستخدام المسؤول لخدمات وسائل التواصل الاجتماعي ووضع أساليب للحد من إنتشار الأخبار الكاذبة. في ضوء نتائج الدراسة وتوصياتها يقترح الباحثان إجراء دراسات في الآتي: أثر البرامج التوعوية الصحية في تعديل سلوك الطلاب. الصحة النفسية واستراتيجيات التكيف لدى طلاب المرحلة الجامعية في ظل جائحة كورونا. دور تفشي الجائحة في التحصيل الأكاديمي.

المراجع:

صليحة، القص. (T ا • ץ). فعالية برنامج تربية صحية في تغيير سلوكيات الخطر وتنمية الوعي الصحي لاى المراهقين. أطروحة دكتوراه غير منشورة. جامعة محمد خيضر بسكرة، بسكرة.

التميمي، عبدالجليل مرتضى. (ب99 (1). المسؤولية الاجتماعية لدى طلبة الجامعة وعلاقتها ببعض المتغيرات. مجلة العلوم

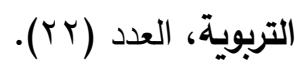

جابر، عبدالحميد جابر • (910 (). سيكولوجية التعلم ونظريات التعليم. القاهر : دار النهضة العربية للنشر والتوزيع. الثايب، ممتاز • (r r). المسؤولية الاجتماعية وعلاقتها بتظيم الوقت. رسالة ماجستير غير منشورة. جامعة دمشق، دمشق. 


$$
\text { إبراهيم، زكريا. (·191 ). علم النفس الاجتماعي. القاهرة: دار المعارف. }
$$

سعيد، محمود محمد. (V . . . ( ). قوة الأنا والثعور بالمسؤولية والضبط الزائد (العدائية) لاى المراهقين المعوقين بصريا والمبصرين. رسالة ماجستير غير منشورة. الجامعة الأردنية، عمان.

الرفاعي، نعيم. ( ( . . ץ). الصحة النفسية :دراسة في سيكولوجية التكيف. دمثق: مطبعة جامعة دمثق.

برقاوي، خالد يوسف. (^ . . ץ). آراء الثباب الجامعية حول المسؤولية الاجتماعية. الملتقى السنوي لمراكز الأحياء بمكة المكرمة. مكة المكرمة.

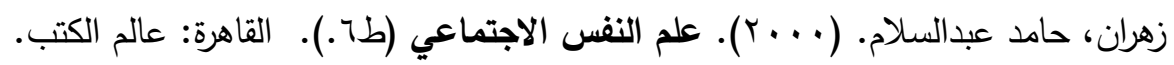

اللحياني، أزهار صلاح. (1 (1 + (). التفكير الأخلاقي وعلاقته بالمسؤولية الاجتماعية في ضوء بعض المتغيرات الأكاديمية لاى عينة من طالبات جامعة أم القرى بمدينة مكة المكرمة. رسالة ماجستير غير منشورة. جامعة أم القرى، مكة المكرمة. الخراشي، وليد عبدالعزيز • (ع . . ؟). دور الأنثطة الطلابية في تنمية المسؤولية الاجتماعية: دراسة ميدانية على عينة مختارة من طلاب جامعة الملك سعود. رسالة ماجستير غير منشورة. جامعة الملك سعود، الرياض.

Ahmad, M. I., Naseem, M. A., Rehman, R. U., Zhuang, W., Ali, R., \& Manzoor, M. S. (2021).

Risk perception of international medical students about coronavirus (Covid-19) in china and their willingness to fly back. Risk Management and Healthcare Policy, 14, 503-510. https://doi.org/10.2147/RMHP.S278338

Bavel, J. J. V., Baicker, K., Boggio, P. S., Capraro, V., Cichocka, A., Cikara, M., Crockett, M. J., Crum, A. J., Douglas, K. M., Druckman, J. N., Drury, J., Dube, O., Ellemers, N., Finkel, E. J., Fowler, J. H., Gelfand, M., Han, S., Haslam, S. A., Jetten, J., ... Willer, R. (2020). Using social and behavioural science to support COVID-19 pandemic response. In Nature Human Behaviour (Vol. 4, Issue 5, pp. 460-471). https://doi.org/10.1038/s41562-020-0884-z

Breakwell, G. M. (2014). The psychology of risk. Cambridge University Press.

Brewer, N. T., Chapman, G. B., Gibbons, F. X., Gerrard, M., McCaul, K. D., \& Weinstein, N. D. (2007). Meta-analysis of the relationship between risk perception and health behavior: The example of vaccination. Health Psychology, 26(2), 136-145. https://doi.org/10.1037/0278- 
Corlett, J. A. (2013). Responsibility and Punishment (4th ed.). Springer.

Darker, C. (2013). Risk Perception. In M. D. Gellman \& J. R. Turner (Eds.), Encyclopedia of Behavioral Medicine. Springer. https://doi.org/10.1007/978-1-4419-1005-9_866

Deng, R., \& Ritchie, B. W. (2018). International university students' travel risk perceptions: An exploratory study. Current Issues in Tourism, 21(4), 455-476. https://doi.org/10.1080/13683500.2016.1142939

Ding, Y., Du, X., Li, Q., Zhang, M., Zhang, Q., Tan, X., \& Liu, Q. (2020). Risk perception of coronavirus disease 2019 (COVID-19) and its related factors among college students in China during quarantine. In PLoS ONE (Vol. 15, Issue 8 August). Public Library of Science. https://doi.org/10.1371/journal.pone.0237626

Dryhurst, S., Schneider, C. R., Kerr, J., Freeman, A. L. J., Recchia, G., van der Bles, A. M., Spiegelhalter, D., \& van der Linden, S. (2020). Risk perceptions of COVID-19 around the world. Journal of Risk Research, 23(7-8), 994-1006. https://doi.org/10.1080/13669877.2020.1758193

Edwards, W. (1961). Behavioral decision theory. In P. Farnsworth, O. McNemar, \& Q. Mcnemar (Eds.), Annual review of psychology (Vol. 12, pp. 473-498). Annual Reviews, Inc. https://doi.org/10.1146/annurev.ps.12.020161.002353

Ferrer, R. A., \& Klein, W. M. P. (2015). Risk perceptions and health behavior. Current Opinion in Psychology, 5, 85-89. https://doi.org/10.1016/j.copsyc.2015.03.012

Gaube, S., Lermer, E., \& Fischer, P. (2019). The Concept of Risk Perception in Health-Related Behavior Theory and Behavior Change. In M. Raue, B. Streicher, \& E. Lermer (Eds.), Perceived Safety: A Multidisciplinary Perspective (pp. 101-118). Springer. https://doi.org/10.1007/978-3-030-11456-5_7

Han, Q., Zheng, B., Agostini, M., Bélanger, J. J., Gützkow, B., Kreienkamp, J., Reitsema, A. M., van Breen, J. A., Collaboration, P. C., Leander, N. P., Belanger, J. J., Gutzkow, B., Kreienkamp, J., Reitsema, A. M., van Breen, J. A., Corona team, P., \& Leander, N. P. (2021). Associations of risk perception of COVID-19 with emotion and mental health during the pandemic. Journal of Affective Disorders, 284(October 2020), 247-255. 
https://doi.org/10.1016/j.jad.2021.01.049

Helweg-Larsen, M., \& Shepperd, J. A. (2001). Do moderators of the optimistic bias affect personal or target risk estimates? A review of the literature. Personality and Social Psychology Review, 5(1), 74-95. https://doi.org/10.1207/S15327957PSPR0501_5

Kahneman, D., Slovic, P., \& Tversky, A. (Eds.). (1982). Judgment under uncertainty: Heuristics and Biases. New York: Cambridge University Press.

Martarelli, C. S., \& Wolff, W. (2020). Too bored to bother? Boredom as a potential threat to the efficacy of pandemic containment measures. Humanities and Social Sciences Communications, 7(28). https://doi.org/10.1057/s41599-020-0512-6

Niño, M., Harris, C., Drawve, G., \& Fitzpatrick, K. M. (2021). Race and ethnicity, gender, and age on perceived threats and fear of COVID-19: Evidence from two national data sources. SSM - Population Health, 13. https://doi.org/10.1016/j.ssmph.2020.100717

Rana, I. A., Bhatti, S. S., Aslam, A. B., Jamshed, A., Ahmad, J., \& Shah, A. A. (2021). COVID19 risk perception and coping mechanisms: Does gender make a difference? International Journal of Disaster Risk Reduction, 55, 102096. https://doi.org/10.1016/j.ijdrr.2021.102096

Renner, B., \& Schupp, H. (2011). The perception of health risks. In H. Friedman (Ed.), The Oxford handbook of health psychology. (pp. 637-665). Oxford University Press.

Rodriguez-Besteiro, S., Tornero-Aguilera, J. F., Fernández-Lucas, J., \& Clemente-Suárez, V. J. (2021). Gender differences in the covid-19 pandemic risk perception, psychology and behaviors of spanish university students. International Journal of Environmental Research and Public Health, 18(8). https://doi.org/10.3390/ijerph18083908

Severino-González, P., Romero-Argueta, J., Villalobos Antúnez, J. V., \& Garrido-Véliz, V. (2020). Social responsibility of higher education students. Motivations for its development in times of COVID-19 in Chile and el salvador. Utopia y Praxis Latinoamericana, 25(Extra 7), 439-452. https://doi.org/10.5281/zenodo.4009788

Sharot, T. (2011). The optimism bias. In Current Biology (Vol. 21, Issue 23, pp. R941-R945). Cell Press. https://doi.org/10.1016/j.cub.2011.10.030

Singkun, A., Payodeuramae, F., Samae, N., Patiwikriwong, P., Chainapong, K., \& Weerakhachon, P. (2020). Social responsibility behaviors among universities students in the 
3 southern border provinces of Thailand in the period of corona virus 2019 (COVID-19) pandemic. Walailak Journal of Science and Technology, 17(9), 979-989.

https://doi.org/10.48048/wjst.2020.10066

Slovic, P., \& Peters, E. (2006). Risk perception and affect. Current Directions in Psychological Science, 15(6), 322-325. https://doi.org/10.1111/j.1467-8721.2006.00461.x

Soltan, E. M., El-Zoghby, S. M., \& Salama, H. M. (2020). Knowledge, Risk Perception, and Preventive Behaviors Related to COVID-19 Pandemic Among Undergraduate Medical Students in Egypt. SN Comprehensive Clinical Medicine, 2(12), 2568-2575. https://doi.org/10.1007/s42399-020-00640-2

Sternberg, R. J., \& Sternberg, K. (2012). Cognitive Psychology (6th ed.). Wadsworth, Cengage Learning.

Tadese, M., Haile, A. B., Moltot, T., \& Silesh, M. (2021). Perceived risk of covid-19 and related factors among university students in ethiopia during school reopening. Infection and Drug Resistance, 14, 953-961. https://doi.org/10.2147/IDR.S302126

Taghrir, M. H., Borazjani, R., \& Shiraly, R. (2020). COVID-19 and iranian medical students; A survey on their related-knowledge, preventive behaviors and risk perception. Archives of Iranian Medicine, 23(4), 249-254. https://doi.org/10.34172/aim.2020.06

Weinstein, N. D. (1980). Unrealistic optimism about future life events. Journal of Personality and Social Psychology, 39(5), 806-820. https://doi.org/10.1037/0022-3514.39.5.806

WHO. (2020a). Pneumonia of unknown cause - China. Retrieved April 24, 2021, from https://www.who.int/csr/don/05-january-2020-pneumonia-of-unkown-cause-china/en/

WHO. (2020b). Statement on the second meeting of the International Health Regulations (2005) Emergency Committee regarding the outbreak of novel coronavirus (2019-nCoV). Retrieved April 24, 2021, from https://www.who.int/news/item/30-01-2020-statement-on-the-secondmeeting-of-the-international-health-regulations-(2005)-emergency-committee-regardingthe-outbreak-of-novel-coronavirus-(2019-ncov)

WHO. (2020c). WHO COVID-19 Dashboard. Retrieved April 20, 2021, from https://covid19.who.int/

WHO. (2020d). WHO Director-General's opening remarks at the media briefing on COVID-19- 
11 March 2020. Retrieved April 24, 2021, from https://www.who.int/directorgeneral/speeches/detail/who-director-general-s-opening-remarks-at-the-media-briefing-oncovid-19---11-march-2020

WHO. (2021). Weekly Operational Update on COVID-19 (Issue 51). Retrieved April 19, 2021, from https://www.who.int/publications/m/item/weekly-operational-update-on-covid-19--19-april-2021

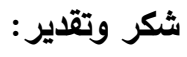

يتقدم الباحثان بالثكر والتقدير للدكتور هاجر إدريس يوسف، الدكتور محمد طاهر، الأستاذ سوماهورو أيوب، والأستاذ إبراهيم جون على ما قدموا من تعليقات واقتراحات مفيدة ساعدت بشكل كبير في إثراء الورقة.

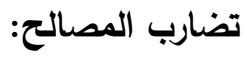
يقر الباحثان بعدم وجود تضارب في المصالح. 